\title{
The National Russian Model of University at the Era of Academic Capitalism
}

\author{
Svetlana Sharonova ${ }^{1,2, *}$, Elena Nazarova ${ }^{3}$, Nataly Erokhova ${ }^{1}$ \\ ${ }^{1}$ Faculty of Social Sciences, St. Tikhon's Orthodox University, Russia \\ ${ }^{2}$ Institute of World Economy and Business, People's Friendship University of Russia, Russia \\ ${ }^{3}$ Russian Academy of National Economy and Public Administration, Russia
}

Copyright $\mathrm{O} 2015$ by authors, all rights reserved. Authors agree that this article remains permanently open access under the terms of the Creative Commons Attribution License 4.0 International License

\begin{abstract}
The transformation of the national model of Russian University is under the influence of academic capitalism. The very same academic capitalism was born in the depth of the neoliberal capitalism. The basic principles of the neoliberalization were fully implemented within the transformation of national educational systems: - An arrangement of conditions to accumulate capital and political power in economic elite circles; - A denial of the concept of nation, and, consequently, a promotion of an idea that the government interference in economy is dangerous (in this case in the form of minimization government interference in education); - Assistance in independent and stable functioning of the whole education system including all the levels and elements (schools, institutes, universities, etc.). In Russia and other countries, this leads to the destruction of national educational systems. E. Durkheim said that if in society there are many cultures than each of them which have its own education system. G. Simmel argued that cultural diversity enriches the world community. However the implementation of neoliberal policy in the field of education under the slogan of "globalization" ignores the law and seeks to simplify the interaction between the educational systems in order to achieve clarity and transparency of market exchange. Author analyzes on the example of Russia the trends that resulted from the modernization of the education system that implements neoliberal principles and creates academic capitalism. Virtually neoliberal utopian promises in practice lead to quite the opposite, rather than expected results.
\end{abstract}

Keywords Neolibiralization, Academic Capitalism, National Education System, Globalization, Modernization

\section{Neoliberal Principles}

Neoliberal policy in the field of culture (which also includes education) has led to not commercialization only, i.e. "transformation of cultural goods from the status of relatively free to not free", but also to displacement of recipient of these goods "from an independent person to a consumer with neutral cultural affiliation" [1].

The basic principles of neoliberal policy are:

- An arrangement of conditions to accumulate capital and political power in economic elite circles;

- A denial of the concept of nation, and, consequently, a promotion of an idea that the government interference in economy is dangerous (in this case in the form of minimization government interference in education);

- Assistance in independent and stable functioning of the whole education system including all its levels and elements (schools, institutes, universities, etc.).

This neoliberal policy brings a total marginal character to all educational system when marginality serves as the constitutional principle of organization of an educational space.

Marginality of executors means that those who are directly involved in educational process - should recruit a large number of practitioners in teaching process (in accordance with the requirements of Bologna process), i.e. persons who have no work experience at the university.

Marginality of technologies used by executives means that they borrow technologies that are previously not typical for certain disciplines and other fields of science not necessarily related.

Marginality of developing fields is the prevalence of interdisciplinary spaces in educational programs and practices.

The principle of marginality is neither accidental nor spontaneous, which is the result of construction of knowledge development model. Classical model, which was fundamental until the 20-30s of the last century, was built on the principle of the independence of each field of science. Modernist model originated from the beginning of the $20^{\text {th }}$ century and being widely developed until the beginning of the $21^{\text {st }}$ century considered interdisciplinary approach as a 
search for explanations of the phenomenon by another science language. It was a look from the outside. The current model uses the principle of interdisciplinary approach as an opportunity to build new fields of scientific knowledge. This is the stage of mixed knowledge where traditional fundamental knowledge of the classical model is transferred to the rank of applied science: a new fundamental knowledge is formed for every newly formed independent interdisciplinary direction.

All the mentioned factors together: neoliberal policy, marginality and modern model of knowledge gradually lead to the elimination of disciplinary and professional division in education. The current model is based on the following principles:

- Interdisciplinary approach in scientific disciplines (as already discussed);

- Flexibility in the curriculum based on the principle of "here and now" (which means an annual revision of curriculum according to short-term changes of labor market requirements);

- Later professional scientific specialization because technological aspects of knowledge are in focus (due to the fact that "here and now" changes more actively takes place in technology especially under the influence of the rapidly developing computer knowledge than in fundamental scientific knowledge even in the sphere of a new interdisciplinary space).

Thus in contemporary neoliberal policy, an opposition to methodological strictness of classical knowledge is formed. This opposition is based on increased attention to the "immanence of the substrate" which includes open-minded approach, mobile response to a specific inquiry and the ability (patience, desire) to start "from the beginning every time ".

\section{Academic Capitalism}

According to Gary Rhoades and Sheila Slaughter, academic capitalism is a regime, which entails the participation of educational institutions in the formation of market-oriented behavior [2]. Moreover, this type of behavior is transmitted not only to the students, but is primarily extended to the educational organizations.

Reduced state funding for education, serious loss of its support resulted in self-survival of educational institutions not only in Russia but also abroad. The use of non-academic elements of consumption (e.g. logos, t-shirts, coffee mugs, etc.) was typical for Western universities in the past, so the transition to a new level of income sources from the main educational and scientific research functions was not much of a problem. However, this transition has led to major changes in academic practice, where income issues are of greater importance than process of getting broad and deep knowledge. In addition, there was a substitution of the concept of "access to education" to the concept of "accessibility to education", where expanded access to education among students facing economic, social and cultural barriers changes to an affordable and convenient way to obtain education for people working in business and be able to pay for educational services.

However, as noted by Gary Rhoades and Sheila Slaughter revenue growth of educational institutions does not mean revenue growth of entrepreneurship, business and society as a whole. Firstly, the internal resource market has certain limitations, meaning both qualitative ability of applicants and the financial capacity of the population. Part of the problem relates to economic constraints achieved by attracting foreign students, who are able to pay a higher price for obtaining educational services. Secondly, the desire to reduce the cost educational programs leads to an underestimation of the requirements of the standards to increase the proportion of young teachers without scientific degrees, graduate students in the faculty of the university. US Department of Education and the National Center for Education Statistics see an additional source of income in the development of models of online learning, by involving groups, which are not members, but eager to join the ranks of the middle class.

Negative trends of academic capitalism manifested in the search for legal possibilities to commercialize university copyright teaching materials. Intellectual products of staff of the universities are beginning to be considered as intellectual property of the university, since the creation of these products used "institutional resources".

Academic capitalism has a negative impact, as noted by Gary Rhoades and Sheila Slaughter in their study, on the most fundamental and democratic order of the Academy, violates the logic of educational development: the formation of a critical, analytical thinking, the continuity and consistency of the input subjects. All this contributes to sawing teaching discipline into individual short-term elements (seminars, practices) that are taught by invited experts from outside.

\section{Retrospective Review of Russian University Model}

First of all, it should be noted that model of university is not only a system of organization of educational process but mostly a system of scientific knowledge process. In the first Charter of Moscow University (1755) we can find an example of Russian university model, where the principles of German universities were adopted:

- Education - is a science, not ascertaining of facts, correlation research, finding causes, reasons and deductions;

- Methodology of scientific knowledge are independent scientific researches of professors, where students are involved;

- Content of education is knowledge of basic 
fundamental principles and decrees of nature, methods of scientific knowledge.

As a matter of fact Moscow University had a legal independence. It was subordinated to the state organization to the Senate. Professors, teachers and students were removed from the general jurisdiction and were subjected only to the university court. University staff was tax-free both from monetary taxes and taxes in kind.

All the further history of this model was accompanied by a struggle with the government for the preservation of the autonomy and freedom of scientific knowledge. Changes made by the adoption of the new Charters of 1804, 1819, 1835 limited the independence and freedom of the University's staff, and immunity of jurisdiction was lost. The Charter of 1863 restored though not entirely the former autonomy but in the 1880s universities were given under the direct control of the officials again. The Statement of 1905 restored independence of the University in the questions of elections of the rector instead of the assignment, competitive staff recruitment, but all these measures did not bring calm to the University's life. As we can see the entire struggle before the Revolution of 1917 concerned only legal issues, which did not affect the management of scientific knowledge content.

The October Revolution has brought significant changes in the system of higher education of the country. Law schools were vanished, and instead of them faculties of Social Sciences were opened. Professors assigned by the Revolutionary administration were mostly people with no teaching experience and scientific research skills. Admission to universities was free - open to all citizens who have reached the age of 16, regardless of their knowledge background. Thus at Moscow State University thirty-six thousands of students were registered in 1919, and this index was in four times higher than the marginal rate. Because of the poor training students failed and dropped their studies after the entrance to the University. From 66 thousands of students admitted to universities only 315 graduated (according to $1919^{\text {th }}$ statistics). Preparing work departments were opened to improve the situation. But at the same time exams were not required, only in the case of approbation of the student they could be held on. According to the two Decrees adopted in the fall of 1920 the Professors' Council as the main authority of the University was abolished. A special committee was founded to recruit a new staff. Moscow State University's special committee was composed of 11 members - two of them were professors, others were the representatives of the party, public and the government organizations.

1925 was a crucial moment in Russian school history. "Business executives" who needed experts - "specialists", supported the university tradition. Gradually the quality of education has increased. But in 1929 a new expansion of communism took place: lectures were replaced by "brigade studies", "manufacturing practices" began to dominate over the "theory". Political literacy was the main professional criterion. In 1932 this policy resulted in "complex of incapacity" among the new generation of "red specialists".

During the Soviet period the original model of Russian university not only lost its legal autonomy but also an ideological independence in the field of social and humanitarian knowledge. Nevertheless we are more likely to claim that the cognitive culture formed in the original model continued to exist even in these hard conditions. Due to this model, specific national features of Russian education as fundamentality and encyclopedic knowledge were formed.

The concept of this encyclopedic knowledge is an orientation of Russian education mostly on enlightenment than on specialization. Enlightenment is fully agreed with the mentality of Russian education causes "an inherent human desire for the truth, rightness, goodness, and smartness ... Therefore, because of this enlightenment all spheres of education and specialization are connected. From this point of view it doesn't matter who you are - a scientist or an administrator, a judge or a physician, an actor or a philanthropist and what knowledge you need for your professional activity" [3].

The principle of fundamental knowledge relates to the classical cognition of knowledge within the sphere of autonomous disciplines. Today an interdisciplinary approach splits the fundamental knowledge. Every new interdisciplinary construct is not mostly based on the own fundamental classical disciplinary theory but limited only to the scientific knowledge surface. The logic of such style of studying has got mostly an acquainted but not thorough and logical character. Here we've got an economic, legal, environmental, etc. literacy, along with computer literacy and an ability of driving car. Instead of cognition and worldview development as main scientific ideas at the end of the XIX - early XX centuries the functional ability to find specific information has formed. Sacral and heuristic character of knowledge has transformed into information search. But the paradox is as an education gets more fragmented, superficial character than the fundamental knowledge gets more value.

\section{Modernization Trends in Modern Russian Education}

The processes of modernization of Russian education were coincided with the collapse of the Soviet Union state. A need of modernization was imminent. The concept of the Unified labor school born in 1918 was fully implemented in 1974. Society has changed significantly from political and commercial point of view. At that moment one of the main education problems was the problem of preparing highly skilled workers. Attempts of raising the prestige of primary professional education organizations were successful, but the result didn't pay all the investments. Not everyone worked according to getting specialty, many falling for the general boom considered this step as a level of getting higher education. On practice, educational system lost the concept of the state goal; it continued to exist by inertia. 
In the 1990s an alternative to the communist concept of education could only be the neoliberal policy, which in turn was originated as a critique of capitalist society and perceived very positively. Thus the Law of Education (Ed. 1991) reflects on one hand the desire to vanish everything that characterized the communist model of education (strict content standards of curricula and courses, unified elements of all levels of education, censorship of textbooks for humanities, etc.), on the other hand an establishment of neoliberal policy as a methodological foundation of the education. For example, the principle of non-state interference of the education system was seen both on the ideological and the funding levels. Those who got the political power were so aggressive to any reflection of the Communist Party ideology that "along with the water splashed out the child"; any ideology of education including state ideology was abandoned. In terms of financial support educational organizations just survived. With no experience in business and marketing, universities and schools began to earn money from the rent, commercial services included into educational process, new commercial offices, branches, etc.

The principle of free development and functioning of the whole education system and all its elements has led to the fact that every educational organization was free to work out their own curricula, textbooks, methods of teaching and forms of organization. A great amount of gymnasiums, schools, educational complexes, etc., declaring themselves as innovative and unique have appeared. Mass school has lost its relevance. Private sector of educational organizations prospered.

The greatest hopes were associated with this development of private sector in education that was considered as the most appropriate form for the educational needs of the developing market economy; it differed significantly in content, methodical, organizational, material and technical aspects from the existing state education sector and was aimed to satisfy the educational needs of the new generation of youth raised in different socio-economic conditions[4].

At this moment there was a substitution of the concept of "access to education" to the concept of "accessibility to education".

The next stage of modernization of Russian education is associated with transition to Bologna process. The creative ideology replaced the destructive one. That time the state was not able to formulate its own goal of the Institute of Education which would contribute to the reproduction of society. The economy of early 1990s was in severe crisis too and it was impossible to expect from economic elite to express the social order. Bologna process was the best mechanism for the purpose of modernization of Russian education. At this stage the education institute purpose was substituted by the modernization process purpose.

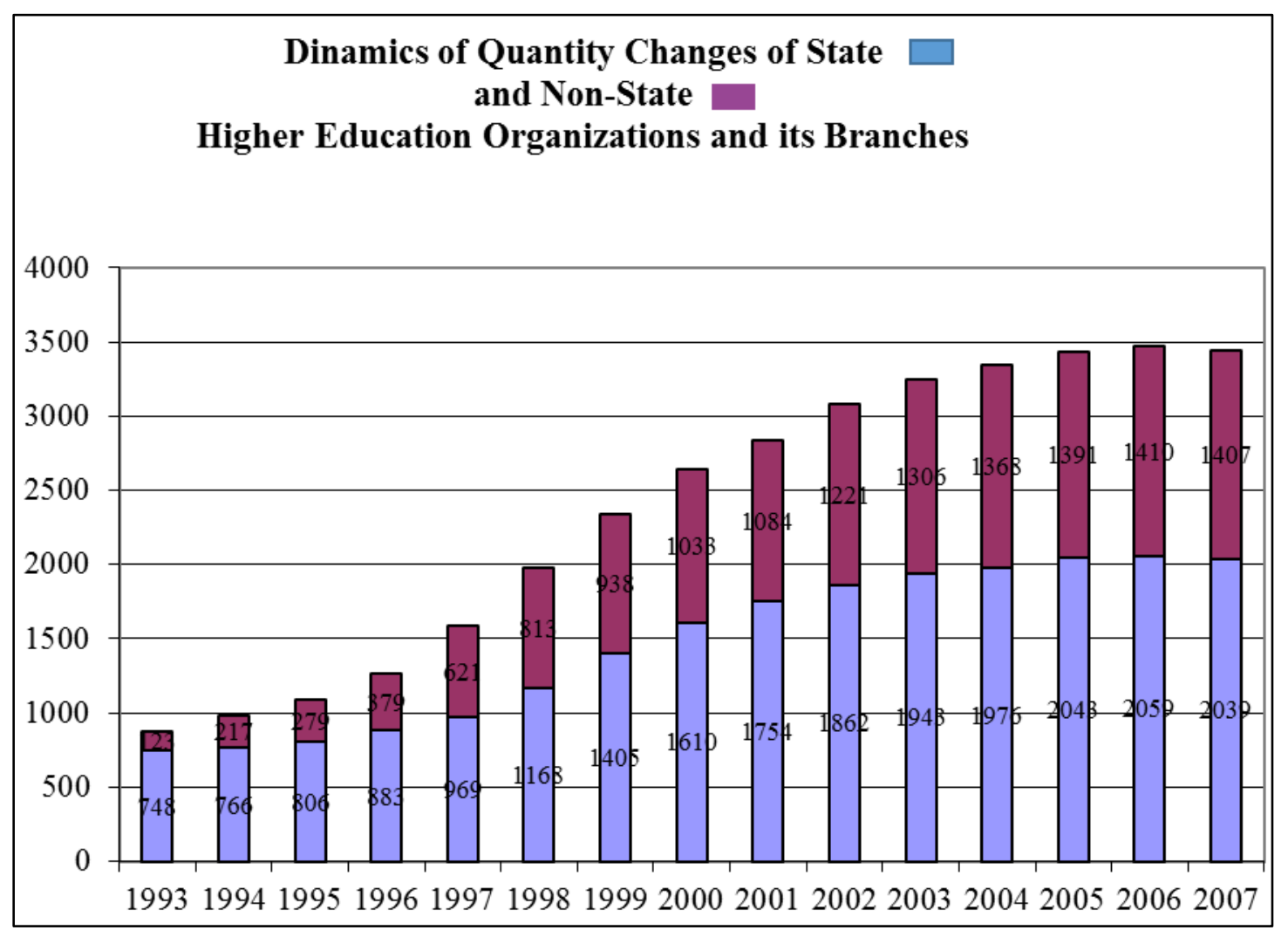

Figure 1. Dynamics of Quantity Changes of State and Non-State Higher Education Organizations and its Branches 
The Federal Law dated by January 13, 1996 «Of Amendments and Additions to the Law of the Russian Federation "Of Education"» finally legitimized the concept of "availability of education", the previous term of "access of education" from the document of 1992 was withdrawn. Moreover the term of accessibility of education was balanced by the concept of "adaptability of the education system to the levels of study and training skills of students and pupils." Thus another substitute was made: not a personal development became the aim of education but an adaptation of educational system to the present human capital of the country. An individual was considered not as an object of education but as a condition of education. Within the framework of neoliberal policy this situation allowed to open the floodgates for the development of commercial structures in the higher education field (Fig. 1).

A new morality has formed in the society: the student does not pay for access of education but for access of obtaining a certificate of education. Accordingly, the adaptation of the educational system took place in this direction as in market relations "the customer is always right".

The process of marginality has begun with the use of new educational standards. New standards of education didn't affect the content of disciplines as it was in the Soviet Union. These standards were created on the basis of European standards, which determine frames, rules and principles of organization of educational process in order to test activities of educational organizations. Many national systems of education of Europe created difficulties in the labor market for its inadequacies in educational process. Therefore an idea of finding unified standards for the structure, curricula and teaching process conditions prevailed. And at this level in the law of education of the Russian Federation there was a substitution of responsibility of the quality of education by the quality of offered educational services. The concept of "educational minimum" (which legitimized and justified in fact decrease of the responsibility of educational institutions for the quality of education in general) has appeared. The number of founders of educational organizations was unlimited. Autonomy of educational institutions extends to subsidiaries, branches and structural divisions until the full implementation of the powers of a legal entity with a separate account and balance sheet. It was the apotheosis of neoliberal policy. The system of higher education was covered by greed. At the state universities and institutions corruption began to flourish. Rating of Russian universities started to fall down (Table 1).

Objective view of the level of school education can serve PISA test data for the countries of the OECD (Organization for Economic Cooperation and Development), in which Russia has been participated for 10 years. During this period Russian pupils were not ranked above 29. Test results show that pupils not only from Europe but also from East Asia are better than pupils from Russia.

Table 1. World Rankings of the Leading Universities

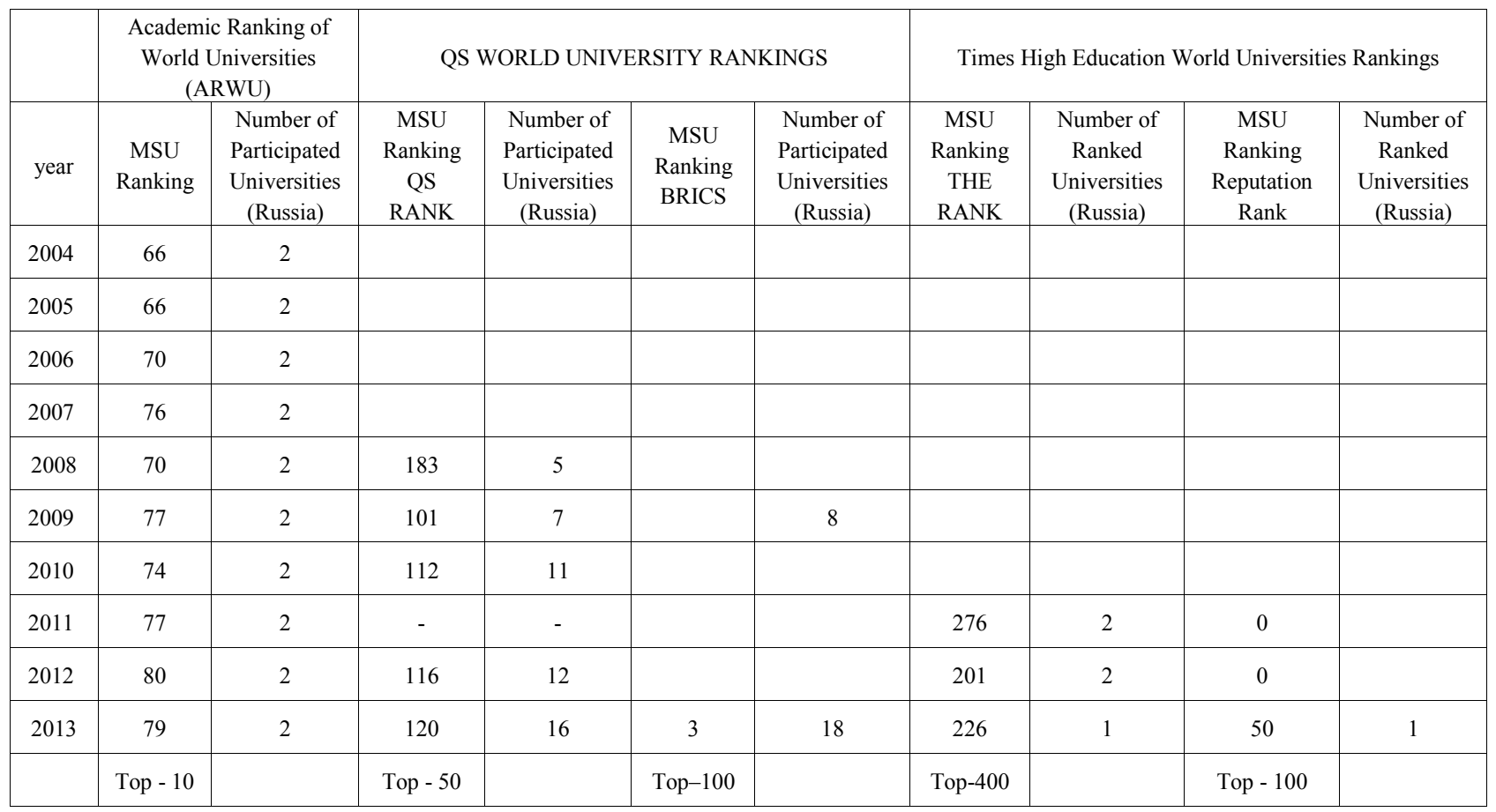


Since 2009 the government has been concerned about the state of affairs in the higher education. According to experts [5] the global market of higher education has reached $\$ 50$ billion, and by 2015 it could rise up to $\$ 200$ billion. The rank of leading positions in the global market of higher education is the following: USA, Great Britain, Germany, France, Australia, China, Japan, Russia and Canada. Russian universities are not competitive in this business. Table 1 shows the results of the world rankings of the leading universities; an example of the Moscow State University $(\mathrm{MSU})^{1}$ shows that Russian higher education has got strong historic brand of the leading university of the country (50th place), if we take a look on objective indicators we can be proud of the $3 \mathrm{~d}$ place among the developing countries only.

The great amount of new universities caused by the neoliberal policy in the aftermath of demographic failure of 90 s was recognized as not profitable. The reduction of the branches of the universities that began in $2008-2009^{2}$ is expected to continue. Based on the decision of the Interdepartmental Commission's Session for monitoring an effectiveness of educational organizations for higher education ${ }^{3} 45$ universities and branches require optimization of its activities and 373 branches are found to be ineffective and reorganization is recommended.

The following features characterize marginal constructivism of educational reality of Russia during this period:

- No goals of reforming education

- Chaotic copying of foreign experience

- Mosaic fragmentation of legislation (Ministry of Education and Ministry of Social Development)

- Destruction of the strict standards that formed meritocracy ideology of education

- Destruction of the principles of fundamental and encyclopedic knowledge.

- The predominance of situational education system

- Increased stratification benchmarks in education

- The principle of immanence in the reformation / modernization of the education system

The new Education Act of 2013 is the new turning point in the modernization of Russian education. One of the indicators is the fact that an opportunity to study on the payment basis becomes the prerogative of higher education ${ }^{4}$.

$1 \mathrm{MSU}$ is chosen as the first rank university in the National Rating of Russian universities.

2 In 2008 the Federal Education Agency closed 36 branches of the universities within the Agency's jurisdiction and 50 more branches were closed in the first half of 2009. Besides more than 400 representative offices of Russian universities were closed.

3 On January 13, 2014 on the official website of the Ministry of Education and Science of the Russian Federation The Report of the Interdepartmental Commission's Session for monitoring an effectiveness of the educational organizations for higher education was published.

4 In the Russian Federation accessibility and gratuity are guaranteed in accordance to the Federal state educational standards of preschool, primary general, basic general and secondary general education, secondary professional education, as well as on a competitive basis free higher education if the citizen receives this level of education for the first time (Art. 5, cl.3 of the Federal Law "Of Education").
The terms of "access" and "accessibility" in the context of the state policy in the sphere of education are replaced by guarantees of the right for education. In fact, the government takes again its obligations and responsibilities for the state and development of the education system in society.

However the new law of education extends and legitimizes the marginal state of educational content, the boundaries of the curriculum are not strictly determined because an educational organization is responsible for it. Regulatory mechanisms controlling the content of education based on the expansion of the "autonomy of educational organizations...", on the "freedom of choice of education according to the needs and inclinations of a person ...", "democratic character of the management of education ...". Thus there is a destruction of the monolith of educational knowledge, and values of education are split in general.

\section{Conclusions}

Utopia of neoliberal policy of education is that an activation acted by an educational organization of its own scientific and educational resources is not only able to provide additional sources of financing, but also to put academic knowledge on the needs of economics. Examples of Russia and other countries show that the search of additional economic resources leads to destruction of the foundation of academic knowledge, to destruction of the integrity and identity of national educational systems. An arrangement of conditions to accumulate capital and political power in economic elite circles show that this power and capital do not work for the government but promote the process of withdrawal of business and capital abroad, and also to activate the "brain drain".

Utopia of academic capitalism is that an economic independence of educational organizations, its academic freedom and democratic principles of management are based on universal cultural value, thereby they contribute to the development of globalization, as opposed to the process of reproduction of society in accordance with national cultural traditions.

\section{REFERENCES}

[1] Bikbov A. Cultural Policy of Neoliberalism. http://permm.ru/menu/xzh/arxiv/83/kulturnaya-politika-neoli beralizma.html

[2] Rhoades G., Slaughter Sh. Academic Capitalism in the New Economy: Challenges and Choices / American Academic, 1, $1,2004$.

[3] Stoyunin V. Ya. Notes about Russian School // Anthology of Pedagogical Thought of Russia of the second half of XIX and the beginning of XX centuries - M.: Pedagogics, 1990. P.81.

[4] Stepanov V.I. Development problems of non government 
educational organizations in Russia and CIS countries. [6] Federal Law «Of Education» (1992 Version). http://aeli.altai.ru/nauka/sbornik/2000/stepanov.html

[5] Aidrus I.A., Filippov V.M. The World Educational Market. Studing Book. M.: People's Friendship University of Russia,

[7] Federal Law «Of Education» (1996-2002 Version). 2008 .

[1] Bikbov A. Cultural Policy of Neoliberalism. http://permm.ru/menu/xzh/arxiv/83/kulturnaya-politika-neoliberalizma.html

[2] Rhoades G., Slaughter Sh. Academic Capitalism in the New Economy: Challenges and Choices / American Academic, 1, 1, 2004. P. 37-60.

[3] Stoyunin V. Ya. Notes about Russian School // Anthology of Pedagogical Thought of Russia of the second half of XIX and the beginning of XX centuries - M.: Pedagogics, 1990. P.81.

[4] Stepanov V.I. Development problems of nongovernment educational organizations in Russia and CIS countries. http://aeli.altai.ru/nauka/sbornik/2000/stepanov.html

[5] Aidrus I.A., Filippov V.M. The World Educational Market. Studing Book. M.: People's Friendship University of Russia, 2008. P.6. 